\title{
Os folhetos de cordel editados pelo Projeto Memória da Universidade Federal do Rio Grande do Norte: um estudo de capas
}

The cordel leaflets edited by Memory Project of the Universidade Federal do Rio Grande do Norte: a cover study

\author{
Gabriel Gurgel Dimas, Elizabeth Romani
}

cordel, xilogravura, design, acervo

\begin{abstract}
Este artigo apresenta um estudo sobre as capas dos folhetos de cordel editados pelo Projeto Memória da Universidade do Rio Grande do Norte, entre os anos de 1980 e 1982. Para esta pesquisa, foi estabelecido um recorte temporal que auxiliou na sistematização da análise gráfica ao longo dos três anos de sua existência. Portanto, esse estudo tem como objetivo analisar o design da capa desenvolvida pela EDUFRN, estabelecendo um paralelo entre suas peculiaridades e o folheto popular. A investigação da identidade gráfica dessas capas confirmou a manutenção das características apregoadas ao moderno folheto de cordel brasileiro: uma publicação de no máximo 16 páginas, no formato $16 \times 12 \mathrm{~cm}$, baixo custo de produção e predomínio da xilogravura.
\end{abstract}

cordel, woodcut, design, collection

This article presents a study of the covers of the cordel brochures edited by the Memory Project of the Universidade Federal do Rio Grande do Norte, between the years of 1980 and 1982. For this research, it was established a timespan that aided in the systematization of graphic analysis throughout the three years of its existence. Therefore, this study aims to analyze the cover design developed by EDUFRN, establishing a parallel between its peculiarities and the popular brochures. The research of the graphic identity of these covers confirmed the maintenance of the characteristics presented in the modern Brazilian cordel brochures: a publication of a maximum of 16 pages, in the $16 \times 12 \mathrm{~cm}$ format, low cost of production and predominance of woodcut.

\section{Introdução}

O folheto popular é um dos principais atributos da cultura nordestina, oriunda de uma tradição europeia que chegou ao Brasil com a colonização portuguesa. A produção de suas capas revela o saber vernacular que condiz com as áreas do conhecimento abordadas pelo design, tornando-se parte da história das oficinas gráficas nordestinas. Tal produção é o resultado de fatores históricos, sociais e econômicos da região em que os cordéis eram impressos, além de traduzirem essas razões em suas narrativas e gravuras.

O marco na produção dos cordéis ocorreu com a popularização da indústria gráfica de folhetos, quando as impressoras de menor porte se espalharam pelo interior e passaram a ocupar a posição das grandes folhetarias. Franklin (2008) afirma que, a partir da década de 1950, houve a democratização do processo produtivo de cordéis. O autor relata ainda que, uma década depois do aumento da produção, o interesse da elite brasileira pela xilogravura foi despertado a partir da publicação, em Paris, do cordel Via Sacra pelo Mestre Noza.

As circunstâncias de impressão foram se afastando da realidade das oficinas do interior e, em razão da queda nas vendas, a indústria do cordel entra em franca decadência nos anos de 1970 (Franklin, 2008). Deste modo, o processo de impressão dos cordéis deixou de ser uma iniciativa popular, transformando-se em objeto de estudos que buscam a identidade cultural nordestina. Com o passar dos anos, as características de sua produção foram mudando para se adaptar às novas realidades de mercado: "[...] a queda da demanda que se segue naturalmente ao desenvolvimento social e econômico" (Hallewell, 2005: 649). O autor justifica que a redemocratização no país contribuiu com o declínio do poder de atração dos folhetos, 
uma vez que o cordel foi um veículo de expressão do descontentamento popular. Assim, a sua veiculação torna-se cada vez mais institucionalizada e financiada pelas instituições públicas e leis de fomento cultural.

Neste contexto, entre 1980 e 1982, ocorreu a execução do Projeto Memória da Universidade do Rio Grande do Norte (UFRN) com o propósito de reeditar alguns títulos pertencentes à coleção de Diógenes da Cunha Lima, na oficina gráfica da editora universitária, atual EDUFRN. Apesar da inexistência de qualquer registro de tal projeto, acredita-se que sua motivação principal foi divulgar a cultura dos folhetos populares. Os cordéis publicados neste período foram incorporados ao acervo de obras raras da Biblioteca Central Zila Mamede (BCZM). Além disso, o projeto teve como desdobramento a catalogação do acervo de cordéis, passando então a ser considerado como fonte informacional.

Neste artigo, será exposta uma relação comparativa entre o projeto gráfico das capas produzidas pelo Projeto Memória da UFRN em seus diferentes anos. O objetivo deste estudo é analisar as capas, mostrando como se deram os ajustes no design, incorporando novos modos de reprodução, e estabelecer algumas relações gráficas observadas no corpus com a história dos cordéis. A pesquisa pretende contribuir com a reflexão sobre os folhetos populares, considerados importantes objetos de estudo para a construção da história dos impressos no nordeste.

\section{Procedimentos de pesquisa}

O corpus analisado foi composto por 32 títulos, que correspondem às edições publicadas dentro do Projeto Memória. Todos os exemplares seguem o mesmo padrão de produção gráfica, impressão e acabamento. De acordo com Alves (2017), todos os cordéis editados neste período reproduzem na íntegra o miolo, porém, a capa ganhou um novo design com intuito de identificar a procedência da edição. Explica ainda que as capas foram montadas segundo projeto gráfico proposto na editora e foram produzidas com uma impressora offset.

A investigação da identidade gráfica da literatura de cordel impressa pela EDUFRN, entre os anos de 1980 e 1982, adotou as seguintes etapas metodológicas: revisão bibliográfica para compreender a história dos folhetos populares e suas características gráficas predominantes nos cordéis brasileiros; seleção do corpus com intuito de obter uma análise mais detalhada; registro fotográfico de todas as capas encontradas na BCZM; tratamento das imagens com a finalidade de eliminar as interferências visuais; e análise das capas a partir de atributos formais.

Tal estudo teve como ponto de partida a coleta de dados na BCZM, local onde concentra a maior coleção do objeto de estudo. Tal biblioteca utiliza a divisão em eixos temáticos seguindo o modelo de catalogação proposto por Ariano Suassuna. Entretanto, optou-se por seguir uma análise temporal do Projeto Memória, pois notou-se que as mudanças perceptíveis nas capas se alteram por ano de publicação. Ademais, foram levantados dados por meio de uma entrevista semiestruturada com o designer aposentado da editora, Olavo Alves de Oliveira, e com o pesquisador de literatura de cordel, Everardo Ramos.

O tratamento de dados envolveu a seleção e edição das capas em grupos por unidade gráfica, agrupando por semelhança estética. A obtenção de informações nas capas, a partir da observação dos atributos formais e posterior comparação entre peças, serviu de base para comparação entre as edições e posterior avaliação da estrutura gráfica. Esses dados foram organizados seguindo a divisão espacial: superior, inferior e central.

\section{Projeto Memória}

O Projeto Memória editou 32 títulos, sendo: 16 em 1980; 10 em 1981; e 6 em 1982. Os impressos analisados não fogem das características apregoadas ao moderno folheto de cordel brasileiro, de acordo com Hallewell (2005): uma publicação de no máximo 16 páginas, no formato $16 \times 12 \mathrm{~cm}$, com baixo custo de produção. É interessante notar que, apesar da substituição do processo de composição e impressão, dos tipos móveis para o paste-up, a EDUFRN optou em manter a publicação em uma única cor, bem como o posicionamento das informações: título, autor e imagem. 
Para que esses folhetos obtivessem a chancela da universidade, foram implantadas algumas adaptações, tais como: as capas deveriam refletir uma unidade gráfica semelhante ao que ocorre em coleções editoriais, buscando um caráter que as unificasse e as identificasse como coleção. Alves (2017) relata que esses cordéis não mantiveram as capas originais, sendo adaptadas para destacar as informações institucionais e fornecer unidade para o conjunto desses elementos, tais como: o nome da universidade, autoria do cordel, nome da coleção, nome do projeto e, em alguns casos, o apoio de outras intuições como a Fundação Capitania das Artes (Funarte).

Dentre todos os títulos analisados, encontra-se um predomínio da xilogravura, sendo localizado também o emprego de fotografia. As gravuras se assemelham à Escola de Caruaru: imagens mais "limpas" e marcadas por figuras dominantes e solitárias (Lopes, 1994). Além disso, observou-se o predomínio dos elementos vazados sobre os preenchimentos. A presença da xilogravura, em detrimento de outras técnicas de ilustração, pode estar relacionada à valorização desta pelos intelectuais brasileiros a partir da década de 1950 (Ramos, 2008). As mesmas gravuras foram reproduzidas também no formato de cartão postal (Fig. 1), indicando o autor da gravura e o título do cordel ao qual pertence em seu verso.

Figura 1: Exemplo de postal (1980).
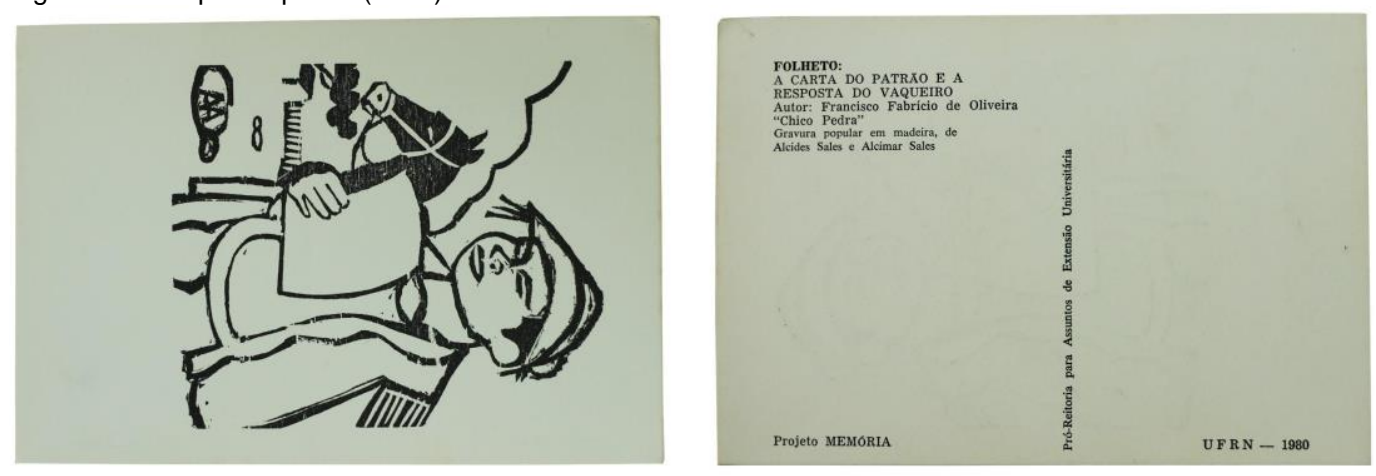

Quanto à organização dos elementos na capa, percebe-se um modelo quase fixo do nome do autor e do título, na parte superior, ambos em caixa alta, sendo o último com altura de corpo maior do que o primeiro, com a intenção de fornecer destaque. Já no centro, é possível observar o uso de uma gravura popular ou fotografia. Na parte inferior, estão as informações institucionais, tais como: "Universidade do Rio Grande do Norte", "Pró-Reitoria de Assuntos Externos", "Projeto Universitário", "Projeto Memória", "Coleção Literatura de Cordel" e "Apoio Funarte".

Constata-se que, ao longo dos anos, houve algumas mudanças na inclusão e na eliminação de informações nas capas. No ano de 1980 (Fig. 2), por exemplo, na parte superior da capa, acima da imagem, adotou-se como padrão gráfico a inscrição "Autor popular", antecedendo o nome do autor e o título, com predomínio da versão em caixa alta, muito embora essa mesma região não mantenha nenhum padrão tipográfico. Na parte inferior, encontra-se o nome da universidade, Projeto Memória e Coleção Literatura de Cordel. É interessante notar ainda que a parte inferior não se altera nos diversos títulos, atuando de maneira semelhante a uma marca.

As publicações de 1981 (Fig. 3) apresentam o mesmo projeto gráfico do ano anterior, incluindo, na parte inferior da capa, a informação institucional "Pró-Reitoria para assuntos de Extensão Universitária". Em alguns casos, notou-se a substituição do "Projeto Memória" por "Projeto Universitário", além da inclusão do "Apoio Funarte", no entanto, essas intervenções textuais foram variáveis durante esse ano.

Os folhetos de 1982 (Fig. 4) foram marcados por um projeto gráfico mais inconsistente diante do padrão já estabelecido. As capas desvinculam-se da referência de coleção e passam, cada uma, a ter mais autonomia entre si. Assim, muitas das capas produzidas neste período não apresentam nenhuma informação institucional além do autor. Observa-se também o uso da caligrafia em detrimento da composição tipográfica, apresentando uma produção de caráter gestual. Deste modo, torna-se nítida a desarticulação do projeto gráfico, o que leva a crer que vincular as edições com o Projeto Memória não era mais prioridade. 
Figura 2: Exemplos de capas produzidas em 1980.
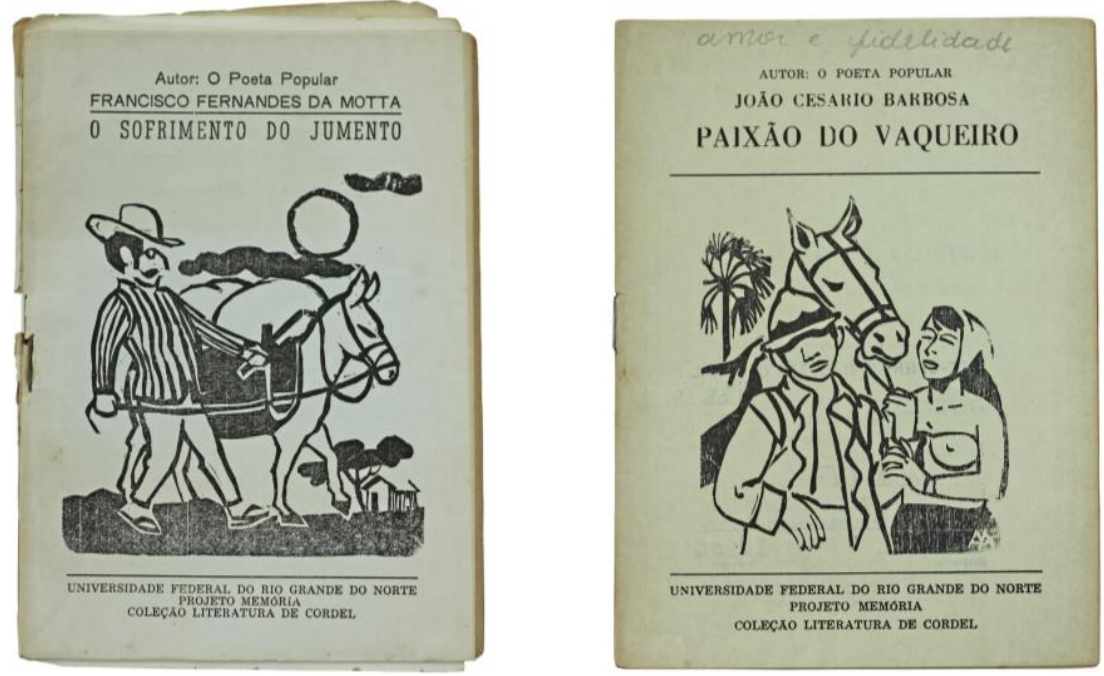

Figura 3: Exemplos de capas produzidas em 1981.
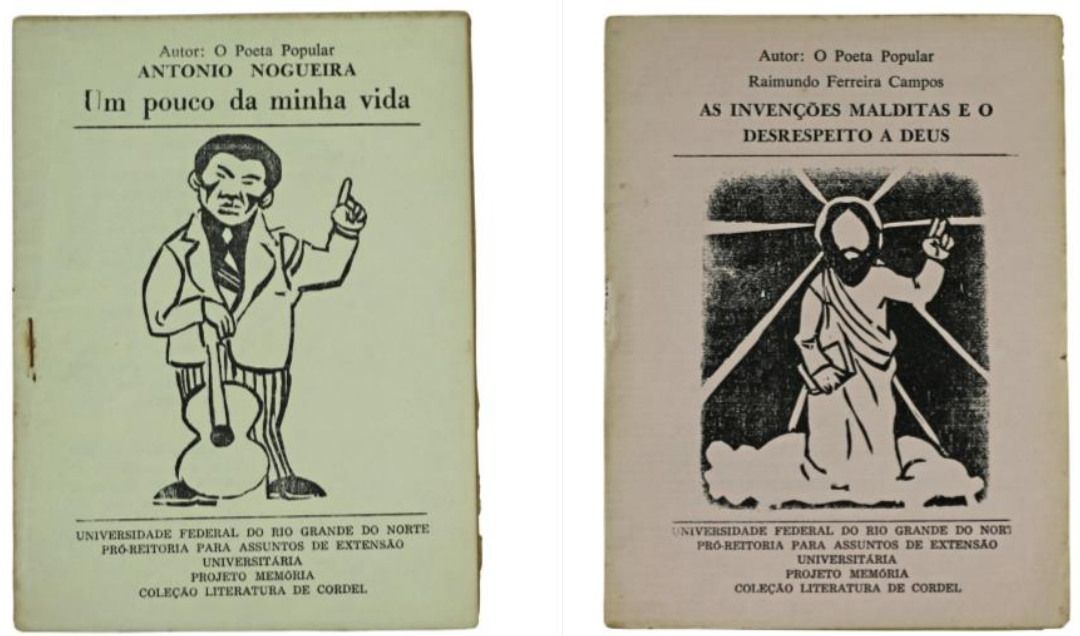

Figura 4: Exemplos de capas produzidas em 1982.
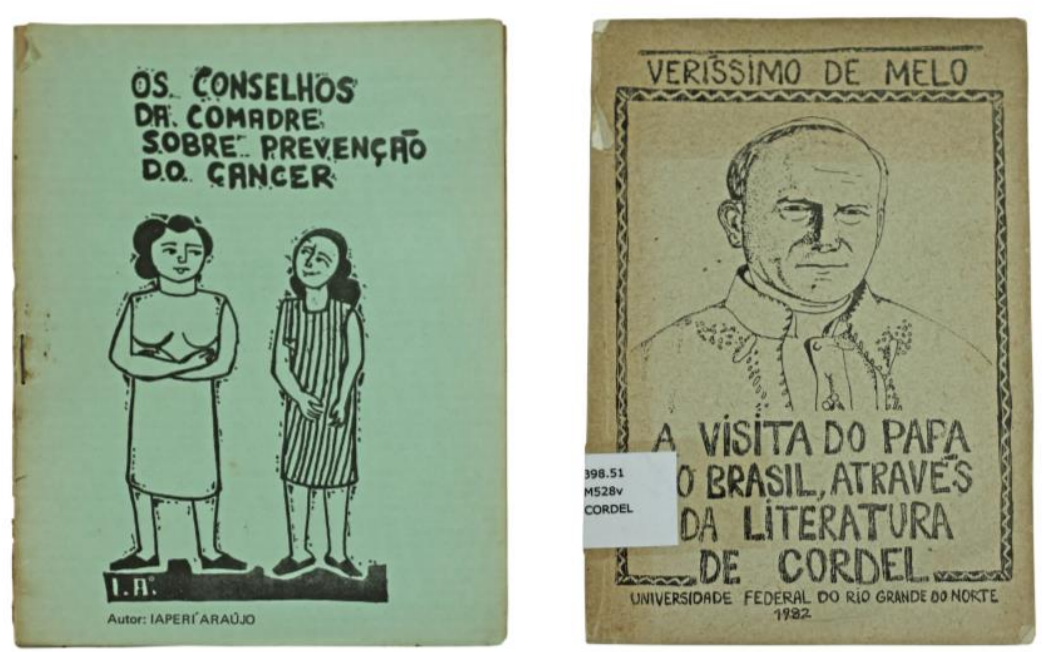

Anais do 8ํㅡㄹ Congresso Internacional de Design da Informação | CIDI 2017

Proceedings of the $8^{\text {th }}$ Information Design International Conference | CIDI 2017 
Durante a análise, notou-se a repetição de gravuras em títulos diferentes, o que, segundo Ramos (2017), é recorrente na Literatura de Cordel. A reutilização das matrizes de xilogravura tem como finalidade a redução de custo com a eliminação da produção de uma nova. Apesar de tornar o folheto mais acessível, nem sempre o significado da imagem representava o conteúdo do cordel.

No caso das capas $O$ Bárbaro Crime de Goianinha e O Hediondo Crime de Caicó, no qual foi vítima a menor Rita Reges (Fig. 5), a gravura faz alusão à palavra "crime". No entanto, a representação de um homem estrangulando uma mulher com um pedaço de pano apresenta maior coerência com o conteúdo do primeiro. Entretanto, a cena se aplica a ambos adjetivos atribuídos a palavra "crime", tanto "bárbaro" quanto "hediondo", transmite um teor de violência representado na imagem.

Figura 5: O hediondo crime de Caicó (1980) e Bárbaro crime em Goianinha (1981).
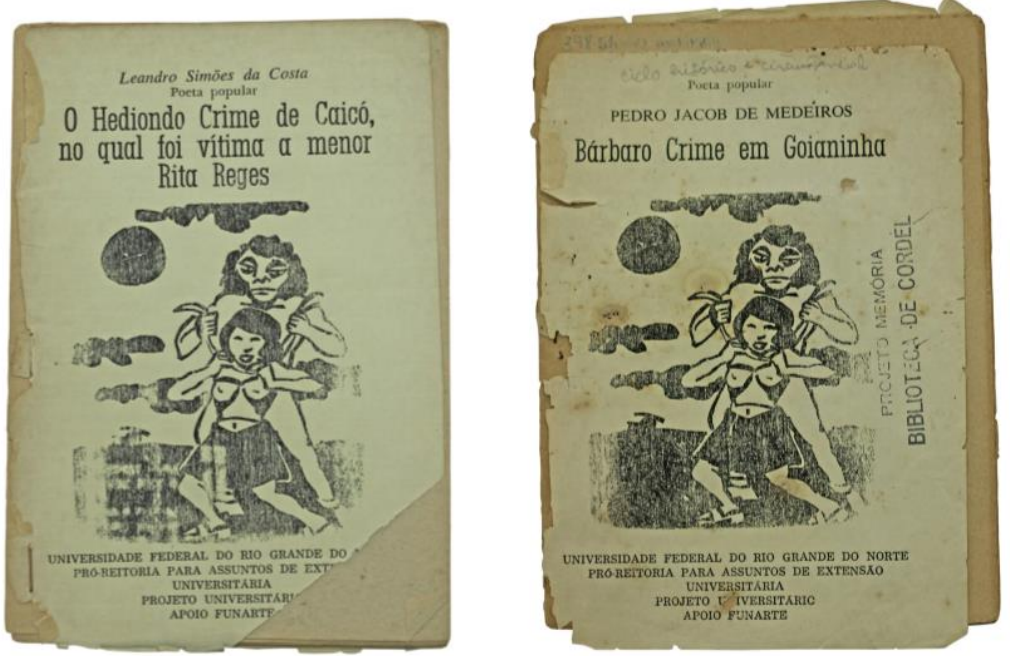

De maneira semelhante, nos títulos Tremor de terra em Natal e Desastre de um Carro que Matou uma Criança na Rua Caiçara (Fig. 6), ocorre a repetição da imagem, mas neste caso, não existe coesão de significado entre imagem e texto. A gravura está descontextualizada com o título, pois não existem pontos lógicos que reverberam a sua utilização. A imagem representa um grupo de pessoas sentadas e agachadas, sem fornecer dados de quem são aquelas pessoas ou onde estão, o que a torna enigmática, não permitindo ao leitor interpretar o significado da gravura sem o apoio do texto.

Figura 6: Tremor de terra em Natal (1980) e Desastre de um Carro que Matou uma Criança na Rua Caiçara (1982).
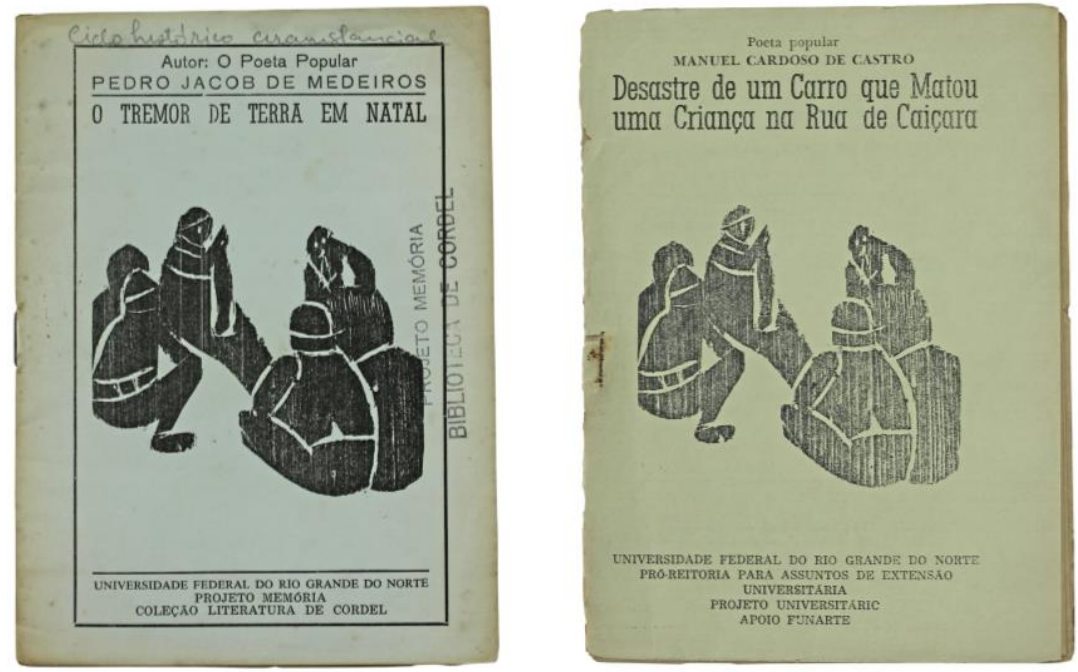

Anais do 8ํㅡㄹ Congresso Internacional de Design da Informação | CIDI 2017

Proceedings of the $8^{\text {th }}$ Information Design International Conference | CIDI 2017 


\section{Considerações finais}

O panorama das capas editadas pelo Projeto Memória fornece uma mostra da valorização dos folhetos de cordel sob a ótica de intelectuais brasileiros, em que muitas das qualidades apreciadas foram retomadas, especialmente o uso da xilogravura. Além disso, notou-se a manutenção do formato $16 \times 12 \mathrm{~cm}$, da quantidade de páginas por publicação e do caráter de baixo custo, mesmo com a substituição do processo de impressão. Apesar do estudo estabelecer uma dimensão em três anos de produção, o corpus permitiu discutir muitos dos pontos propostos no projeto gráfico, como semelhanças e diferenças entre eles. Este estudo não se esgota aqui, cabendo pesquisar as influências das artes gráficas, principalmente do design de periódicos e história da tipografia. Além disso, no futuro, pretende-se estudar a relação entre as capas originais e as capas produzidas no projeto, na tentaria de compreender as escolhas gráficas adotadas.

\section{Agradecimento}

Agradecemos aos servidores da Biblioteca Central Zila Mamede que cooperaram nesta pesquisa, bem como aos entrevistados Everardo Ramos e Olavo Alves.

\section{Referências}

ALVES, O. O. 2017. Entrevista concedida a Gabriel Gurgel Dimas e Elizabeth Romani. Natal, 12 maio 2017.

FRANKLIN, J. 2008. Cem anos da xilogravura na literatura de cordel. In: Nemer, S. (org.). Recorte contemporâneos sobre o cordel. Rio de Janeiro: Edições Casa de Rui Barbosa.

HALLEWELL, L. 2005. O Livro no Brasil: Sua história. São Paulo: Edusp.

LOPES, J. R. 1994. Literatura de Cordel Antologia. 3ed. Fortaleza: Banco do Nordeste do Brasil.

RAMOS, E. 2017. Entrevista concedida a Gabriel Gurgel Dimas e Elizabeth Romani. Natal, 23 jun. 2017. 